\title{
Determinants of Physical Activity among Middle School Girl Students in Iran Based on Social Cognitive Theory in 2018
}

\author{
Research Article
}

\section{Hashemian Maryam ${ }^{1}$, Abdolkarimi Mahdi ${ }^{2}$, Asadollahi Zahra ${ }^{3}$, Nasirzadeh Mostafa ${ }^{4^{*}}$}

\begin{abstract}
1. M.Sc Student of Health Education, Department of Health Education and Health Promotion, School of Health, Student Research Committee, Rafsanjan University of Medical Sciences, Rafsanjan, Iran.

2. Assistant Professor, Department of Health Education and Health Promotion, School of Health, Rafsanjan University of Medical Sciences, Rafsanjan, Iran.

3. Academic Member, M.Sc. Department of Epidemiology and Biostatistics, Rafsanjan University of Medical Sciences, Rafsanjan, Iran.

4. Assistant Professor, Department of Health Education and Health Promotion, School of Health, Occupational Environment Research Center, Rafsanjan University of Medical Sciences, Rafsanjan, Iran.
\end{abstract}

\begin{abstract}
Introduction: Physical activity is one of the most fundamental health promoting behaviors influenced by behavioral, environmental and individual determinants. The present study was conducted to determine the factors affecting physical activity among middle school girl students based on social cognitive theory in Rafsanjan city in 2018. The present cross-sectional study was carried out among 325 middle school girl students through multi-stage sampling; required data was collected using a questionnaire containing three sections of demographic characteristics, standard questionnaire of physical activity assessment during the last week and a questionnaire based on the constructs of cognitive social theory; questionnaires were completed through self-report and analyzed at the significance level of $0 / 05$ by SPSS-16 using relevant statistical tests. The mean daily physical activity of students was $24.14 \pm 26.42$ minutes. Spearman correlation test showed a positive and significant relationship between daily physical activity of students with environmental factors, knowledge, behavioral skills, outcome expectation, outcome value, family support, friends support and self-efficacy of students $(\mathrm{P}<0.05)$. Self-efficacy was the strongest predictor of behavior among the structures of the theory. Considering the unfavorable state of physical activity and the results of research, it is highly recommended to design, implement and evaluate interventions based on social cognitive theory in different target groups affecting adolescents (family and friends) in order to increase the physical activity of girl students.
\end{abstract}

Keywords: Social cognitive theory, Physical activity, Students, Teens, Girl, Self-efficacy.

\section{Introduction}

Physical activity is one of the most important health promoting behaviors and one of the most important causes of preventing more than 38 million non-communicable deaths worldwide (1-2). According to $\mathrm{WHO}$, children and adolescents aged 5 to 17 should have a moderate to intense physical activity of at least 60 minutes a day (3). According to scientific sources, about $50 \%$ of women and $36 \%$ of men in the Eastern Mediterranean region do not do sufficient physical activity (4). Totally, $23 \%$ of adults and $81 \%$ of schoolchildren are not active enough (1). According to the results of Sanaeinasab study, $77.7 \%$ to $87.1 \%$ of 12 to 14-year old Iranian adolescents are not active enough and girls had less mobility than boys (5); only $32 \%$ of high school girls were active and the rest did not have sufficient activity in Tarom city (6).

*Corresponding Author:

Nasirzadeh Mostafa,

Assistant Professor, Department of Health Education and Health Promotion, School of Health,

Occupational Environment Research Center,

Rafsanjan University of Medical Sciences,

Rafsanjan, Iran.

E-mail Id: mnasirzadeh13@rums.ac.ir
Regular physical activity reduces the risk of hypertension, cardiovascular disease, stroke, diabetes, colon cancer, depression, and hip and vertebral fractures and helps control weight (1). Inactivity is the main cause of nearly $30 \%$ of ischemic heart disease due to increasing the risk factors; it, also, accounts for $27 \%$ of diabetes and approximately $21-25 \%$ of breast and colon cancers, and is the fourth leading cause of death worldwide (1,7-8). Meanwhile, it is possible to prevent $75 \%$ of deaths occurring due to cardiovascular diseases with appropriate changes in lifestyle, including increased daily physical activity (9-10).

According to the results of the studies, social support and self-efficacy, knowledge and skills, observational learning (effects of family, friends, peers, school parents and the media), outcome expectation and outcome values were reported as determinants of physical activity (11-14).

According to the World Health Organization, doing enough physical activity and regular consumption of fruits and vegetables are two basic indicators that can prevent and diagnose disorders, diseases and obesity, factors which are, in turn, affected by behavioral, environmental and personal determinants (14). Social cognitive theory considers human behavior as the product of dynamic interaction between individual, 
behavioral and environmental factors (15); it is one of most practical theories about physical activity introduced by Bandura in 1963 (16). The constructs of this theory include knowledge, outcome expectation, outcome value, position understanding, environment, self-efficacy, self-efficacy in overcoming barriers, goal setting and emotional adaptation (17). Parsamehr et al study showed that social support and self-efficacy were the most influential factors for physical activity (11). According to the results of Mahdizade et al. study, Selfefficacy turned out to have the highest impact on physical activity (12). Adolescence is a critical time in which the majority of adult behaviors are rooted (18). The growing trend of obesity and overweight among children and adolescents, its strong relationship with lifestyle (including lack of mobility) (3) and its prevalence in the age group of 9-19 has increased significantly from $4 \%$ in 1975 to more than $18 \%$ in 2016 in Iran (19). Regarding the complications and consequences of physical inactivity on adolescent health and the need to identify the main factors affecting physical activity behavior, the present study was conducted to determine the factors affecting physical activity among middle school girl students based on social cognitive theory in Rafsanjan city in 2018; the main objective was to provide efficient and scientific results for authorities, policymakers, families and students to help them in future decisions and increase the rate of physical activity of adolescents.

\section{Materials and methods}

The present cross-sectional study was conducted on 325 middle school girl students in Rafsanjan in 2018; subjects were selected through multi-stage sampling method from Rafsanjan schools in Southern Iran. Being willing to participate in the study and being aged 13 to 16 years old were the main inclusion criteria; failure to answer $20 \%$ of questions a physical activity higher than 3 standard deviations from the mean were the main exclusion criteria. Thus, Out of 350 completed questionnaires, 25 were excluded for the above reasons and the data of 325 middle school girl students in Rafsanjan was included and inserted in the study.

Required data was collected using a questionnaire consisting of 3 parts. After presenting the research objectives, the researcher attended the session in which the questionnaire was completed by the students in order to resolve possible ambiguity. The first part contained 11 questions, including general, family and demographic information. The second part contained self-report questionnaire of physical activity per week (Weekly Leisure Time Exercise Questionnaire), which contained the physical activity rate of 20 light, medium and intense exercises during the week; the reliability of the questionnaire was assessed in Asadpour et al study and turned out to be 0.79 (20).

Light exercise means a mild physical activity that results in a brief rise in heart rate, such as slow walking, fishing, light stroke, and so on. Moderate exercise means mild exercise that results in slight increased heart rate and sweating, such as fast paced, slow cycling, and volleyball. Intense exercise includes hard or heavy sports (intense activity) which lead to significant sweating and heart rate increase, such as running, soccer, climbing, and so on.

The third part of the questionnaire was devoted to evaluating physical activity behavior determinants based on the constructs of social cognitive theory. This questionnaire consisted of 9 constructs including awareness ( 5 questions with multi-choice answers yes, no, and I do not know with a score range of 0-5), environmental factors and behavioral skills (each 3 questions and score range of 3-15), expected outcome (5 questions and score range of 5-25), outcome value (5 questions and score range of 5-25), observational learning (6 questions with score range of 6-30), family support (3 questions with score range of 3-15), support of friends (5 questions with score range of 5-25) and self -efficacy (6 questions with score range of 6-30), responded through 5-option Likert scale (13). Shirvani et al study verified the validity and reliability of this questionnaire; the validity has been assessed and confirmed according to the comments of ten specialists in the domains of health education, physical education and epidemiology, with Cronbach alpha coefficient reported between 0.61 and 0.82 for all structures SCT (environmental factors, the ability to conduct, expected outcome, outcome value, observational learning, and social strengthening and perceived self-efficacy) (13).

Finally, the collected data was analyzed by SPSS16 using statistical parametric Mann-Whitney, KruskalWallis Test, Spearman correlation coefficient and Multiple Linear Regression tests. The significance level was considered to be 0.05 .

\section{Results}

The mean of household size and body mass index of students were $4.60 \pm 0.97$ and $21.16 \pm 4.18 \mathrm{~kg} / \mathrm{m} 2$. Categorizing BMI based on age-specific percentiles of sex in students indicated that 23 subjects $(7.1 \%)$ were skinny, $219(67.8 \%)$ were normal, $47(14.6 \%)$ were overweight, and 34 subjects $(10.5 \%)$ were obese. Table 1 represents the mean physical activity of students based on the demographic variables for the whole students.

The mean daily and weekly physical activity of the students was $169.01 \pm 184.94$ minutes per week and $24.14 \pm 26.42$ per day. The results of KolmogorovSimonov test showed that the daily physical activity of students was not normal $(\mathrm{P}<0.001)$. Non-parametric Kruskal Wallis test and Mann-Whitney tests were used to compare the mean daily physical activity of students at different levels of demographic variables. The only significant relationship was observed between the mean daily physical activity of students with family income ( $p$ $=0.016)($ Table 1$)$. 
Table 1. Comparison of the average daily physical activity of students based on demographic variables

\begin{tabular}{|c|c|c|c|c|}
\hline Variables & Condition & $\mathbf{N}(\mathbf{P})$ & $\begin{array}{c}\mathrm{M} \pm \text { SD of physical activity } \\
\text { (Unit / day) }\end{array}$ & P-value \\
\hline \multirow{3}{*}{ Educational Grade } & Seventh Grade & $102(31.1)$ & $24.91 \pm 25.40$ & \multirow{3}{*}{0.248} \\
\hline & Eighth Grade & $117(35.7)$ & $27.27 \pm 29.52$ & \\
\hline & Ninth Grade & $109(33.2)$ & $20.06 \pm 23.36$ & \\
\hline \multirow{5}{*}{ Father's education level } & Illiterate & $6(1.9)$ & $26.42 \pm 33.46$ & \multirow{5}{*}{0.603} \\
\hline & Elementary & $27(8.5)$ & $29.36 \pm 29.00$ & \\
\hline & Guidance school & $80(25.2)$ & $20.41 \pm 26.78$ & \\
\hline & High school & $115(36.2)$ & $25.91 \pm 26.72$ & \\
\hline & Academic & $90(28.3)$ & $23.06 \pm 25.10$ & \\
\hline \multirow{5}{*}{ Mother's education level } & Illiterate & $3(0.9)$ & $15.71 \pm 2.47$ & \multirow{5}{*}{0.535} \\
\hline & Elementary & $21(6.6)$ & $23.60 \pm 33.05$ & \\
\hline & Guidance school & $57(17.8)$ & $18.39 \pm 18.81$ & \\
\hline & High school & $149(46.6)$ & $24.17 \pm 26.56$ & \\
\hline & Academic & $90(28.1)$ & $28.00 \pm 29.02$ & \\
\hline \multirow{6}{*}{ Father's job } & Self-employed & $172(53.9)$ & $24.45 \pm 27.30$ & \multirow{6}{*}{0.031} \\
\hline & Employed & $82(25.7)$ & $21.57 \pm 23.59$ & \\
\hline & Worker & $20(6.3)$ & $17.07 \pm 26.60$ & \\
\hline & Unemployed & $4(1.3)$ & $43.21 \pm 25.72$ & \\
\hline & Retired & $32(10.0)$ & $25.44 \pm 25.14$ & \\
\hline & Other cases & $9(2.8)$ & $40.20 \pm 37.92$ & \\
\hline \multirow{2}{*}{ Mother's job } & Housewife & $244(75.8)$ & $23.52 \pm 25.61$ & \multirow{2}{*}{0.638} \\
\hline & Employed & $78(24.2)$ & $25.45 \pm 29.24$ & \\
\hline \multirow{4}{*}{ Family income } & Excellent & $51(15.9)$ & $27.43 \pm 27.72$ & \multirow{4}{*}{0.002} \\
\hline & Good & $140(43.8)$ & $27.73 \pm 28.51$ & \\
\hline & Medium & $117(36.6)$ & $18.71 \pm 22.91$ & \\
\hline & Weak & $12(3.8)$ & $22.44 \pm 23.45$ & \\
\hline
\end{tabular}

According to the results of Spearman correlation test, there was a positive and significant relationship between daily physical activity of students with environmental factors $(\mathrm{P}=0.006)$, knowledge $(\mathrm{P}=0.043)$, behavioral skill ( $\mathrm{P}$ $<0.001)$, expected outcome $(\mathrm{P}=0.020)$, outcome value $(\mathrm{P}=0.002)$, family support $(\mathrm{P}<0.0001)$, support of friends $(\mathrm{P}$ $<0.0001)$ and self-efficacy $(\mathrm{P}=0.0001)$ (Table 2).

Table 2. Correlation coefficients between the Average daily physical activity of student with the components of social cognitive theory

\begin{tabular}{|l|c|c|}
\hline \multicolumn{1}{|c|}{ Constructs } & $\begin{array}{c}\text { Mean score } \pm \\
\text { Standard Deviation }\end{array}$ & $\begin{array}{c}\text { The correlation coefficient } \\
\text { (P-value) }\end{array}$ \\
\hline Environmental factors & $15.82 \pm 2.71$ & $\mathrm{r}=0.152 ;(\mathrm{p}=0.006)$ \\
\hline Behavioral Ability (Knowledge) & $16.10 \pm 3.93$ & $\mathrm{r}=0.112 ;(\mathrm{p}=0.043)$ \\
\hline Behavioral ability (behavioral skill) & $8.46 \pm 2.36$ & $\mathrm{r}=0.326 ;(\mathrm{p}>0.0001)$ \\
\hline Outcome Expectation & $25.64 \pm 2.99$ & $\mathrm{r}=0.129 ;(\mathrm{p}=0.020)$ \\
\hline Outcome evaluation & $18.25 \pm 3.60$ & $\mathrm{r}=0.170 ;(\mathrm{p}=0.002)$ \\
\hline Observational learning & $17.33 \pm 4.66$ & $\mathrm{r}=0.044 ;(\mathrm{p}=0.431)$ \\
\hline Social support (family support) & $6.63 \pm 2.94$ & $\mathrm{r}=0.298 ;(\mathrm{p}>0.0001)$ \\
\hline Social support (friend support) & $8.93 \pm 3.14$ & $\mathrm{r}=0.294 ;(\mathrm{p}>0.0001)$ \\
\hline Self-efficacy & $19.14 \pm 5.53$ & $\mathrm{r}=.0264 ;(\mathrm{p}>0.0001)$ \\
\hline
\end{tabular}

Tests: Spearman's Correlation Coefficient

Multiple linear regressions were used to study the effect of cognitive theory and demographic variables on daily physical activity of students. Logarithmic transformation was used first to normalize the dependent variable (daily physical activity of students). Then, necessary assumptions were examined, so that the normal distribution of the frequency of dependent variable (the logarithm of the daily physical activity of the students), the independence of the remainders by Durbin-Watson test (statistic 1.95), the uniformity of the dispersion around the regression line, the absence of multi-collinearity between predictive variables, the normal distribution of remainders, and the absence of outlier views were evaluated against the regression line, and the results indicated that all the assumptions had been reasonably outlined. The results showed that there was a positive, significant relationship between research variable and behavioral skills $(\mathrm{P}=0.012)$, outcome value $(\mathrm{P}=0.007)$, support of friends $(\mathrm{P}=0.008)$, self-efficacy $(\mathrm{P}=$ 0.006), household size $(\mathrm{P}=0.016)$ and the level of education of the father $(\mathrm{P}=0.036)$ and mother $(\mathrm{P}=0.014)$ (Table 3$)$. 
Table 3. The results of the multiple linear regression analysis for the effect of components of Social cognitive theory and demographic variables on the average daily physical activity

\begin{tabular}{|l|c|c|c|c|c|}
\hline Constructs & Not standardized $\beta$ & $\begin{array}{c}\text { 95\% confidence } \\
\text { interval for } \beta \text { not } \\
\text { standardized }\end{array}$ & $\begin{array}{c}\boldsymbol{\beta} \text { stand- } \\
\text { ardized }\end{array}$ & T value & P-value \\
\hline Environmental factors & 0.002 & $(-0.017,0.021)$ & 0.013 & 0.208 & $=0.835$ \\
\hline $\begin{array}{l}\text { Behavioral Ability } \\
\text { (Knowledge) }\end{array}$ & -0.003 & $(-0.016,0.011)$ & -0.025 & -0.389 & $=0.697$ \\
\hline $\begin{array}{l}\text { Behavioral ability } \\
\text { (behavioral skill) }\end{array}$ & 0.030 & $(0.007,0.054)$ & 0.177 & 2.524 & $=0.012$ \\
\hline Outcome Expectation & -0.010 & $(-0.030,0.010)$ & -0.069 & -0.982 & $=0.327$ \\
\hline Outcome evaluation & 0.020 & $(0.005,0.034)$ & 0.174 & 2.726 & $=0.007$ \\
\hline Observational learning & -0.015 & $(-0.028,0.002)$ & -0.171 & -2.296 & $=0.548$ \\
\hline $\begin{array}{l}\text { Social support (friend } \\
\text { support) }\end{array}$ & 0.019 & $(-0.001,0.038)$ & 0.137 & 1.896 & $=0.059$ \\
\hline $\begin{array}{l}\text { Social support (family } \\
\text { support) }\end{array}$ & 0.024 & $(-0.006,0.042)$ & 0.182 & 2.674 & $=0.008$ \\
\hline Self-efficacy & 0.014 & $(0.004,0.023)$ & 0.193 & 2.802 & $=0.006$ \\
\hline Grade & -0.042 & $(-0.105,0.020)$ & -0.080 & -1.333 & $=0.184$ \\
\hline household size & 0.066 & $(0.012,0.119)$ & 0.158 & 2.420 & $=0.016$ \\
\hline $\begin{array}{l}\text { Father's level of educa- } \\
\text { tion }\end{array}$ & 0.065 & $(-0.126,-0.004)$ & 0.165 & 2.109 & $=0.036$ \\
\hline Mother's education level & 0.094 & $(-0.019,0.170)$ & -0.207 & 2.481 & $=0.014$ \\
\hline Father's job & 0.008 & $(-0.026,0.043)$ & 0.029 & 0.474 & $=0.636$ \\
\hline Mother's job & -0.046 & $(-0.169,0.077)$ & -0.048 & -0.734 & $=0.464$ \\
\hline Family income & -0.027 & $(-0.095,0.040)$ & 0.052 & -0.794 & $=0.428$ \\
\hline BMI & 0.001 & $(-0.011,0.012)$ & 0.006 & 0.109 & $=0.914$ \\
\hline
\end{tabular}

Regarding the results represented in Table 3, assuming that other variables are fixed, the amount of physical activity of students increases for one unit in behavioral skills, outcome value, friends' support, selfefficacy, family size and parenting level. Regarding $\beta$ coefficients, it can be said that the level of mother's education and self-efficacy were the most predictive factors among variables to increase the physical activity of the students. Based on the variables inserted in the multiple linear regression model, $22.2 \%$ of the changes in the level of physical activity of the students were explained.

\section{Discussion}

According to the World Health Organization, adequate and regular physical activity, which is by itself influenced by behavioral, environmental and individual determinants, is one of the most important, preventative and determinants of disorders, diseases and obesity (14). Accordingly, the present study was conducted on 325 middle school girl students in Rafsanjan in order to determine factors affecting physical activity based on social cognitive theory. The mass body mass index of students was $21.16 \mathrm{~kg} / \mathrm{m} 2$ and $25.1 \%$ of subjects were overweight and obese. The mean daily physical activity of the students was 24.14 minutes per day, which was lower than the World Health Organization borderline (60 minutes per day). The mean daily physical activity of in Tehran's teenage girls was 42.15 in and the mean weekly physical activity was 127.75 (13). According to the results of Ghafari et al., the mean physical activity of Shahid Beheshti University girl students was 31.85 minutes per day (21). The only significant relationship was observed between the mean daily physical activity of students with family income. There was a positive and significant relationship between daily physical activity of students with environmental factors, knowledge, behavioral skills, outcome expectation, outcome value, family support, friends support and selfefficacy. The results showed that assumed increase of other variables, including the increase in the level of behavioral skills, outcome value, friends support, selfefficacy, household size and parenting level increase the physical activity of students.

The highest mean physical activity was observed at the second and first middle school grades (equal to eight and seventh grade in Iran's overall education course). It seems that lower level of physical activity in the third grade is due to the fact that students get increasing focused on studying in order to achieve a higher grade for choosing a better field of study in the high school. The academic education of the mother was the most promising way to increase the physical activity of the students. Mothers' being aware and educated is more likely to lead to more attention; it turned out to encourage students to carry out health-related activities, including physical activity. Moderate and high family income was also effective, because it could enhance household's economic capacity to buy sports equipment or register teenage in sports clubs.

In regard with comparing the findings of the present study with the results of formerly conducted research and considering only the constructs of social cognitive theory in the model through calculating $\beta$ 
coefficient, behavioral constructs $(\beta=0.189)$, selfefficacy $(\beta=0.178)$, support of friends $(\beta=0.62)$, outcome value $(\beta=0.46)$, turned out to be the most influential factors affecting the rate of physical activity of students. Additionally, environmental factors, knowledge and outcome expectations did not have a significant relationship with physical activity of students ( $p$ value $<0.05$ ); social cognitive theory could account for $19 \%$ of the changes in students' physical activity.

Environmental factors are one of the foundations of social cognitive theory that examines the physical and social conditions surrounding the student, including the supply of sports equipment at home, around the house and school, and having a safe environment around the home for physical activity. The mean score of environmental factors turned out to be 15.82 , which was moderate. The availability of sport equipment at home had the highest score and access to the playground, the park and the gym had the lowest score among the constructs investigated in the present study. According to the results of Shirvani et al, which was conducted on adolescent girls in Tehran, the mean score of environmental factors was 14.75 (13). In Pirasteh et al study, which was conducted on student living in dormitory, $83.4 \%$ stated that dorms are not equipped enough in terms of sports equipment (such as balls, bicycles , skateboard); additionally, $54.1 \%$ of subjects stated that the dormitory was not a safe place for jogging or running (22). In Lubans et al study, which was conducted on adults in Australia, the school environment influenced girls' physical activity (23). Providing a safe environment for home, school and home-to-school environment, equipping schools with sports facilities and providing sport facilities around parks can play an important role in increasing physical activity among students.

Behavioral abilities include awareness and skill in terms of the minimum time and duration of physical activity, physical activity goals and the ability to form a sports team, prepare sports facilities at home and perform physical activity. The mean score of knowledge was 16.10 and the mean score of behavioral skill was 8.46. The level of awareness was moderate, but the level of behavioral skill was undesirably low. The low score of this construct was related to the lack of awareness among adolescents about the necessity of physical activity at all ages, including children and the elderly, and the main objectives of physical activity. The highest score was related to

physical activity at home and the minimum physical activity was observed during adolescence. According to the results of Shirvani et al, which was conducted on adolescent girls in Tehran, the mean score of knowledge was 23.73 and the mean score of skill was 8.15 (13). Low behavioral skills among girls can be attributed to not being held responsible for themselves and being prohibited from doing things like preparing sports facilities. Teachers' training for schools and parents in improving the importance of assigning tasks such as setting up sports teams and preparing sports facilities for adolescents can be helpful.

Expected outcomes refers to what the individual expects from doing physical activity, which includes fitness, academic achievement, energy, more selfesteem, pleasurable feelings and parental happiness; the mean score of this construct was 25.64, the highest score among all the constructs analyzed in the present study. This high score was related to the fun of activities with friends and increased energy and the least was related to its impact on academic achievement. According to the results of Shirvani et al, which was conducted on adolescent girls in Tehran, the expected outcome rate was 19.15 (13). According to the results of Mirzaei Alavijeh et al study, expected outcomes and self -efficacy were among the strongest predictors of physical activity (24). If the student's assignments are based on the correct timing and ability to meet all the needs of the adolescent age group, the individual will not feel worried about the effect of physical activity on his or her academic progression.

Outcome value, the mean score of which was the desirable rate of 18.25 in the present study, is the value the individual attributes to the results of doing physical activity. According to the results of Shirvani et al, which was conducted on adolescent girls in Tehran, the outcome value score was 11.62 (13). The lowest score in this domain was related to the need for parental assistance for activities, and the highest was related to the pleasure of doing physical activity. Nowadays, the majority of teens realize the value of physical activity. Measures should be taken to make physical activity like a normal daily and group activity, such as holding hiking events, holding sports events in parks, and organizing intra and inter-school sports competitions. Teenagers usually tend to do exercises which don't need the help of others; this is met by putting different sport education courses in elementary and secondary education.

Observational learning refers to acquiring the process by which a specific physical activity is carried out by observing parents and peers while doing this exercise. The mean score of this construct was 17.33, which was relatively desirable. The highest score in this part was related to learning through observing friends, and the least was related to the lack of physical activity in relatives. According to the results of Shirvani et al, which was conducted on adolescent girls in Tehran, the observational learning scores were 16.26 (13). Regarding the fact that observing doing physical activity by parents, relatives and peers motivates and conducts these activities in adolescents, it is recommended to organize training sessions for parents and inform them about this issue and the fact that their doing physical activity with teens will increase the rate of physical activity by organizing family sports conferences.

Social support and reinforcement includes encouragements and punishments that the teenager receives from his family and peers for physical activity. The mean score was 6.63 for the support of the family and 8.93 for the support of friends; the support provided by friends had the lowest score among the constructs and was at an undesirable status. The lowest score for this construct was the lack of family support for the activity, and the highest was the encouragement of the family to perform activities by the teenager and doing sports with friends. According to the results of Shirvani 
et al study, the mean family support score was 10.48 and the mean friends' support score was 8.43 (13). Morowati et al study indicated that social support is a strong predictor of physical activity behavior (25) and Parsamehr et al study found that social support was the most influential factor for physical activity (11). The low rate of this construct in the present study can be due to the lack of sports competitions in schools and the lack of encouragement of sports coaches to perform group physical activity of students. Considering the effect of adults and families on the behavior and lifestyle of teenagers, it is recommended to formulate educational programs for parents and sports trainers and organize sports competitions in schools between different classes. Establishing secure environments on the way from home to school and vice versa can affect teens.

Self-efficacy, the score of which was second among all the constructs and was 19.14 , is defined as the confidence of the individual in his ability to perform physical activity. The highest score in this domain was related to the ability to allocate daily time to the activity, and the least was the ability to perform activities during high school assignments. According to the results of Shirvani et al study, the self-efficacy score was 17.42 (13). In Parsamehr et al study, self-efficacy was one of the most influential factors for physical activity (11). In Mehdizadeh et al study, self-efficacy had the greatest effect on physical activity. Therefore, individuals with high self-efficacy are highly motivated to maintain behavior over time (12). Self-efficacy was influential on the intensity of girls to do physical activity in Lubans et al study, which was conducted on Australian adolescents (23). Self-efficacy was also the strongest predictor in Plotnikoff et al and Mirzaei Alavijeh et al studies $(24,26)$. School planning and giving assignments to students should be based on the principles and consideration of hours for recreation and sports for teens. Regarding the effect of self-efficacy in physical activity, sports coaches should not limit students to specific sports and provide the necessary skills training to empower students.

\section{Conclusion}

The mean weekly and daily physical activity of students was 169.01 and 24.14 minutes in order, both of which were lower than the rate recommended by WHO (60 minutes per day); thus, these two variables turned out to be in undesirable status and in need of improvement. The mean body mass index was $21.16 \mathrm{~kg} /$ $\mathrm{m} 2$ and $67.8 \%$ of subjects were in normal range. The only significant relationship was observed between the mean daily physical activity of students with family income. There was a positive and significant relationship between daily physical activity of students with environmental factors, knowledge, behavioral skills, outcome expectation, outcome value, family support, friends support and student self-efficacy; mother's education had the highest prediction power among variables and self-efficacy and social support were the strongest constructs analyzed in the present study. Therefore, it is highly recommended to design, implement and evaluate interventions based on social cognitive theory in different target groups affecting adolescents (family and friends) in order to increase the physical activity of girl students. One of Completing the physical activity questionnaire through self-report and reviewing it within one-week interval was one of the limitations of the present study.

\section{Acknowledgments}

The present paper is a research project registered with ID number of 97221 and the ethics code of IR.RUMS.REC.1397.111 in Rafsanjan University of Medical Sciences. Thereby, the researcher feels obligated to appreciate the cooperation and financial support of the Vice-Chancellor for Research in Rafsanjan University of Medical Sciences, thorough cooperation and support of the Rafsanjan education system, the school administrators and teachers, and all students who collaborated with the research team during the completion of the study.

Funding: This research was funded by Deputy of Vice Chancellor for Research and Technology at Rafsanjan University of Medical Sciences.

Conflict of interest: None declared.

Ethical approval: The Ethics Committee of Vice Chancellor for Research and Technology at Rafsanjan University of Medical Sciences approved the study (IR.RUMS.REC.1397.111).

\section{References}

1. Physical activity. world health organization. 2016. https://www.who.int/news-room/fact-sheets/detail/ physical-activity dated 12-07- 2017 time 12:10 IST

2. Global status report on noncommunicable diseases 2014. world health organization. 2015. http:// www.who.int $/ \mathrm{nmh} /$ publications/ncd-status-report2014/en dated 04-08-2018 time 11:05 IST

3. Agha-Alinejad H, Farzad B, Salari M, Kamjoo S, Harbaugh BL, Peeri M, Prevalence of overweight and obesity among Iranian preschoolers: Interrelationship with physical fitness. Journal Res Med Sci. 2015; 20(4): 334-341.

4. Jafarpour K, Arastoo AA, Gholamnia-shirvani Z, Saki A Araban M, The effect of health education intervention based on the theory of planned behavior to promote physical activity in women's health volunteers of Shushtar health centers. The Iranian Journal of Obstetrics. Gynecology and Infertility. 2016; 37(19): 62-74.

5. Sanaeinasab H, Saffari M, Nazeri M, Karimi Zarchi A, Bradley J, Descriptive analysis of Iranian adolescents' stages of change for physical activity behavior. Journal of Nursing \& Health. 2013; 15(3): 280-285.

6. BashiriMoosavi F, Farmanbar R, Taghdisi M H, AtrkarRoshan Z, Level of physical activity among girl high school students in Tarom county and relevant factors. Iranian Journal of Health Education and Health Promotion. Summer, 2015; 3 (2): 133-140.

7. Kokkinos P, Myers J, Exercise and physical activity: Clinical outcomes and applications. Circulation. 2010; 122(16): 1637-1648.

8. Pereira S, Pereira D, Metabolic syndrome and 
physical activity. [Article in Portuguese] Acta Med Port. Sep-Oct, 2011; 24(5): 785-790.

9. Alves AJ, Viana JL, Cavalcante SL, Oliveira NL, Duarte JA, Mota J, et al, Physical activity in primary and secondary prevention of cardiovascular disease: Overview updated. World J Cardiol. 2016; 8(10): 575-583.

10. Tian X, Du H, Li L, Bennett D, Gao R, Li S, et al, Fruit consumption and physical activity in relation to all-cause and cardiovascular mortality among 70,000 Chinese adults with pre-existing vascular disease. PLoS One. 2017; 12(4).

11. Parsamehr M, Niknajad M, hedat A, Investigating the relationship between cognitive-social patterns and promoting the motivation of physical activity among humanities students of Yazd University. 2015; 21(11): 185-192.

12. Mahdizade M, Peyman N, Taghipour A, Esmaily $\mathrm{H}$, Mahdizade SM, effect of health education program on promoting physical activity among diabetic woman in Mashhad, Iran: Applying Social Cognitive Theory. J Res Health Sci. 2013; 13(1): 90-97.

13. Shirvani H, Sanaeinasab H, Tavakoli R, Saffari M, Khalaji K, Me'mar S, The effect of a social cognitive theory-based educational intervention on the physical activity of female adolescents. Iran Journal of Health Education and Health Promotion. 2016; 4(4): 309-318.

14. 10 facts on obesity 2017. world health organization. 2017. https://www.who.int/features/ factfiles/obesity/en/ Updated October 2017 dated 12-11-2018 time 13:05 IST

15. Glanze K, Rimer BK, Viswanath K. Health Behavior and Health Education: Theory, Reserch, and Practice. 5ed. Usa; Wiley; 2015. 161- 185p.

16. Saffari M, Shojaeizadeh D, Ghofranipour F, Heydarnia A and Pakporhajiagha A. Theories, models and methods of health education and health promotion. 4ed. AsareSobhan Publication; Tehran; Iran; 2012. 100-111p.

17. Sharma M, Romas J. Theoretical Foundations of Health Education and Health Promotion. 2ed. Jones \& Bartlett Publishers; Sudbury; usa; 2017. 160$176 \mathrm{p}$.

18. Kargar M, Moattari M, The effect of osteoporosis prevention education by peers and health personnel on self-efficacy of adolescents with nephrotic syndrome. Iranian Journal of Nursing. 2013; 26(81): 44-53.

19. Media centre Fact sheet, Obesity and overweight. world health organization.

https://www.who.int/news-room/fact-sheets/detail/ obesity-and-overweight updated February 2018 dated 12-04-2018 time 12: 20 IST

20. Asadpour M, Sheikh Fathollahi M, Goujani R, Razi S, Torkashvand F, Hassanloei B, et al, Survey on Physical Exercise Among Paramedical Students of Rafsanjan University of Medical Sciences Based on Stages of Changes Model and Its Association with Self-Efficacy in 2011-2012. Journal of Rafsanjan University of Medical Sciences. 2014; 13(4): 349360.

21. Ghafari M, Nasirzadeh M, Aligol M, Davoodi F, Nejatifar M, Kabiri S, et al, Determinants of physical activity for prevention of osteoporosis among female students of Shahid Beheshti University of Medical Sciences: Application of health belief model. Pajoohande. 2014; 19(5): 244250.

22. Pirasteh A, Johari Z, Zafarghandi N, Kholdi N, Stages of Dairy Products Consumption Change by Medical Students: The Trans Theoretical Model. aumj. 2012; 1(3) :159-165.

23. Lubans D, Okely AD, Morgan P, Cotton W, Puglisi L, Miller J, Description and evaluation of a social cognitive model of physical activity behaviour tailored for adolescent girls. Health education research. 2012; 27(1): 115-128.

24. Mahboubi M. et al, Socio-Cognitive Determinants of Regular Physical Activity among College Students World Family Medicine. 2018; 16(2): 158 -162 .

25. Morowatisharifabad AM, Abdolkarimi M, Asadpour M, Fathollahi MS, Balaee P, The Predictive Effects of Protection Motivation Theory on Intention and Behaviour of Physical Activity in Patients with Type 2 Diabetes. Open Access Maced J Med Sci. Mar, 2018; 6(4): 709-714.

26. Plotnikoff RC, Costigan SA, Karunamuni N, Lubans DR, Social cognitive theories used to explain physical activity behavior in adolescents: A systematic review and meta-analysis. Preventive Medicine. 2013; 56(5): 245-253. 